\title{
Avaliação da irradiação gama em peitos de frangos refrigerados monitorados pela contagem de bactérias heterotróficas aeróbias mesófilas viáveis e $\mathrm{PH}$
}

\section{Evaluation of gamma irradiation of refrigerated chicken's chests monitored by viable heterotrophic aerobic mesophilic bacteria counting and $\mathrm{pH}$}

\author{
Daniele C. de C. PINTO, ${ }^{*}$ Sérgio B. MANO, ${ }^{* * *}, \cdot$ Helio C. VITAL, ${ }^{* * *}$ Luis Antonio T. de OLIVEIRA, ${ }^{* \star * *}$ \\ Maícia V.P de TELLO, ${ }^{*}$ Carolina R. POMBO**
}

\begin{abstract}
Resumo
Pesquisas têm demonstrado que a tecnologia de irradiação de alimentos tem sido eficiente na redução de patógenos na carne de aves. O objetivo desta pesquisa foi estudar o efeito da radiação gama em peitos de frangos desossados, sem pele e refrigerados. Utilizou-se um total de 19 amostras, sendo 12 submetidas à irradiação e as restantes, não irradiadas, utilizadas como controle. A irradiação foi efetuada num irradiador de pesquisa com fonte de césio-137, de forma que as amostras, mantidas constantemente sob refrigeração, recebessem uma dose de 3,0 kGy. A temperatura das amostras foi monitorada durante todo o período do experimento. $\mathrm{Na}$ avaliação bacteriana, utilizou-se a contagem de heterotróficos aeróbios mesófilos viáveis e, como parâmetro físico-químico, realizou-se a aferição do $\mathrm{pH}$. A temperatura registrada no momento da colheita foi de $10,3^{\circ} \mathrm{C}$, e , a partir do primeiro dia, foi mantida entre $-1,5$ e 3,5드. até o $25^{\circ}$ dia. A contagem bacteriana inicial das amostras não irradiadas foi de $6,5 \times 10^{5} \mathrm{UFC} / \mathrm{g}$, apresentando um aumento a partir do primeiro dia e alcançando taxas de $\sim 10^{7} \mathrm{UFC} / \mathrm{g}$ no $5^{\circ}$ dia. A irradiação reduziu a carga bacteriana em 4 ciclos logarítmicos, observando-se inicialmente uma contagem de $2,4 \times 10^{2} \mathrm{UFC} /$ g, a qual atingiu 107 UFC/g no 15 dia de armazenamento. O pH das amostras variou entre 5,9 (no dia zero) e 6,8 (11 e 25 dias depois, para as amostras não irradiadas e irradiadas, respectivamente). De acordo com os resultados, pode-se concluir que a dose de 3,0 kGy, em termos bacteriológicos foi eficaz em prolongar a vida útil do peito de frango em aproximadamente três vezes.
\end{abstract}

Palavras-chave: irradiação; radiação gama; peito de frango.

\begin{abstract}
Several works have shown that the irradiation process is very efficient in reducing pathogenic counts in poultry meat. Thus, this work aimed at investigating the effects of gamma radiation on refrigerated skinless deboned poultry chest. Since the moment of crop, which occurred at $10.3^{\circ} \mathrm{C}$, the samples were kept at temperatures between -1.5 and $3.5^{\circ} \mathrm{C}$ until the $25^{\text {th }}$ day. Nineteen experimental samples were used including 12 irradiated and 7 unirradiated (control) ones. Irradiation to a $3.0 \mathrm{kGy}$ gamma dose was performed in a research ${ }^{137} \mathrm{Cs}$ source-driven facility. Bacterial evaluation was based on heterotrophic aerobics viable mesofilic counts while $\mathrm{pH}$ was selected as a parameter for physical-chemical investigation. The control samples were found to have an initial bacterial load of $6.5 \times 10^{5} \mathrm{UFC} / \mathrm{g}$ which quickly reached $\sim 10^{7} \mathrm{UFC} / \mathrm{g}$ on the $5^{\text {th }}$ day. In contrast, the irradiated samples exhibited an initial count of $2.4 \times 10^{2} \mathrm{UFC} / \mathrm{g}$ which reached $\sim 10^{7} \mathrm{UFC} / \mathrm{g}$ on the $15^{\text {th }}$ day of storage. Thus irradiation was found to reduce the bacterial load $\sim 4$ logarithmic cycles whereas the $\mathrm{pH}$ measurements yielded values which increased from 5.9 (on day zero) to 6.8 ( 11 and 25 days later, corresponding to control and irradiated samples, respectively). Therefore, as long as only bacteriological concerns are taken into consideration, it can be concluded that the dose of 3.0 kGy is effective in approximately tripling the shelf-life of refrigerated skinless boned poultry chest.
\end{abstract}

Keywords: irradiation; poultry irradiation; poultry chest.

* Curso de Pós-graduação em Irradiação de Alimentos da Faculdade de Medicina Veterinária da Universidade Federal Fluminense

** Programa de Pós-graduação em Medicina Veterinária - Mestrado e Doutorado em Higiene Veterinária e Processamento Tecnológico de Produtos de Origem Animal, Universidade Federal Fluminense

***Instituto de Pesquisas e Desenvolvimento - Centro Tecnológico do Exército - Rio de Janeiro, RJ

****Depto. de Tecnologia dos Alimentos, Faculdade de Veterinária, Universidade Federal Fluminense - Rua Vital Brazil Filho, 64, CEP 24230-340, Niterói, RJ - Brasil

- Para quem enviar a correspondência - MTASBM@VM.UFF.BR 


\section{Introdução}

A indústria avícola brasileira é considerada uma das maiores produtoras de carne de frango no mercado mundial. Segundo dados da ABEF (Associação Brasileira dos Exportadores e Produtores de Frango), a produção de 1999, com aproximadamente 5.526 toneladas, foi inferior apenas à dos EUA, com 13.366 toneladas (ABEF, 2002).

De acordo com dados da World Health Organization (WHO), Food and Agriculture Organization (FAO), and International Atomic Energy Agency (IAEA), o frango apresenta uma carga bacteriana inicial relativamente alta na linha de processamento, caracterizada por uma contagem total entre $5,0 \times 10^{5}$ a $1,0 \times 10^{7} \mathrm{UFC} / \mathrm{cm}^{2}$ (WHO/FAO/IAEA, 1989). Dentre as bactérias contaminantes destacam-se a Salmonella spp, Campylobacter spp., Staphylococcus aureus, Clostridium perfringens, Yersinia enterocolitica e Listeria monocytogenes (Germano e Germano, 2001).

Desde 1990, o "Food and Drug Administration" (FDA) aprovou o uso da irradiação para este produto na dose de 3 kGy. A utilização desta dose permite obter-se uma redução do número de bactérias não esporuladas a quantidades tais, que resultam em um prolongamento de até duas semanas no tempo de conservação (FDA, 1990).

Tendo em vista as considerações anteriores, este trabalho tem como objetivo contribuir com maiores informações sobre o uso da irradiação gama (dose de 3kGy - preconizada pelo FDA no ano de 1990) em peitos de frango, sem pele, desossados e mantidos sob refrigeração, monitorados através da contagem de bactérias heterotróficas aeróbias mesófilas viáveis e pH.

\section{Material e métodos}

Foram utilizadas amostras de peito de frango desossado, sem pele e refrigerados, recolhidos na linha de processamento de um matadouro de aves sob inspeção estadual no Estado do Rio de Janeiro. Foi adquirido um total de 19 amostras, embaladas individualmente em sacos de polietileno permeáveis ao oxigênio e pesando em média $350 \mathrm{~g}$ cada amostra.

As amostras foram transportadas em recipientes isotérmicos com gelo até o Centro Tecnológico do Exército em GuaratibaRJ, onde está localizado o irradiador gama de pesquisa do tipo cavidade blindada e com fonte de césio-137 utilizado no experimento. Do total de 19 amostras, 12 foram irradiadas e as restantes não irradiadas, utilizadas como controle, que permaneceram armazenadas no recipiente isotérmico. A irradiação foi efetuada de forma que as amostras, mantidas constantemente sob refrigeração, receberam a dose de 3kGy, sendo a taxa de dose de $2 \mathrm{kGy} / \mathrm{h}$, resultando em um tempo de exposição de 1h54min.

Após a irradiação, as amostras foram identificadas e transportadas em recipientes isotérmicos até o Laboratório de Controle Microbiológico da Faculdade de Veterinária da UFF, onde foram armazenadas sob refrigeração $\left(0 \pm 1^{\circ} \mathrm{C}\right)$. Análises bacteriológicas e de $\mathrm{pH}$ foram realizadas periodicamente.

Para a análise bacteriológica da contagem padrão de bactérias heterotróficas aeróbias mesófilas viáveis utilizou-se a metodologia recomendada pelo Compendium of Methods for The Microbiological Examination of Foods (Swanson et al. In: Vanderzant e Splittstoesser, 1992).
Para a análise físico-química de determinação de pH utilizouse o método potenciométrico, através do potenciômetro marca HORIBA, modelo M13.

A avaliação de temperatura foi realizada introduzindo-se o termômetro no interior da massa muscular do peito de frango previamente embalado, ao final da linha de processamento, e manteve-se a monitoração durante todo período do experimento, 25 dias, registrando-se além da temperatura da amostra, suas variações mínima e máxima.

Os resultados obtidos foram tratados estatisticamente pelo método dos mínimos quadrados para a obtenção de uma regressão linear, utilizando-se a equação de Baranyi (1994) para a determinação dos parâmetros de crescimento, fase de latência e tempo de duplicação, da curva obtida da contagem de bactérias heterotróficas aeróbias mesófilas viáveis.

\section{Resultados e discussão}

Os resultados da contagem bacteriana das amostras controle e irradiadas estão representados na Figura 1 e Tabela 1. Pode-se observar que o grupo controle apresentou, no dia zero, contagem inicial de $3,2 \times 10^{6} \mathrm{UFC} / \mathrm{g}$, e permaneceu estável até o $2^{\circ}$ dia (fase de latência). Registraram-se sinais de deterioração $\left(10^{7} \mathrm{UFC} / \mathrm{g}\right)$ no $4^{\circ}$ - dia. Estes resultados estão em acordo com dados da FAO/OMS/IAEA (apud Tarboush et al., 1996) que citam que as taxas encontradas no frango ainda na linha de processamento variam de $10^{5}$ a $10^{7} \mathrm{UFC} / \mathrm{cm}^{2}$. Entretanto, os resultados obtidos nesta pesquisa para o grupo controle não estão em acordo com os dados da Comission of European Communities (1976) e Gill (1982), que consideram que o frango obtido em boas condições de higiene apresenta concentração logarítmica entre 3,0 e 4,6.

As amostras irradiadas apresentaram contagem inicial (dia

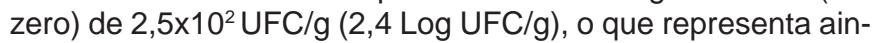
da em acordo com os dados da Comission of European Communities (1976) e Gill (1982) que as amostras irradiadas, em termos bacteriológicos, apresentaram-se em ótimas condições de higiene. Porém deve-se ressaltar que a irradiação não deve substituir as boas práticas de manufatura (GCIAA, 2000).

Ao realizar-se uma comparação entre as amostras controle e as irradiadas quanto à redução na contagem bacteriana, podese verificar que os resultados obtidos evidenciam uma redução de aproximadamente 99,99\% nas amostras irradiadas. Tal resultado está de acordo com Katta et al. (1991), que ao irradiarem amostras de carcaças de frango observaram que mais de $99 \%$ da população bacteriana foi inativada com a dose de 3kGy.

Em relação aos parâmetros de crescimento, determinados através da curva de Baranyi (1994), o tempo de duplicação nas amostras irradiadas foi de $23,5 \mathrm{~h}$, enquanto no grupo controle este foi de $27,1 \mathrm{~h}$. Já a fase de latência das amostras controle se estendeu por um período de aproximadamente $45,6 \mathrm{~h}$, enquanto que das irradiadas, este período foi menor, sendo de 19,2 h, o que leva a suspeitar que parte da microbiota resistente à irradiação teve um período de adaptação menor, apresentando uma menor fase de latência. A contagem (em UFC/g), na fase estacionária de crescimento, no grupo controle alcançou índice logarítmico de 8,5 no $11^{\circ}$ dia, enquanto que valores iguais a 9,0 foram alcançados nas amostras irradiadas somente no $25^{\circ}$ dia (Tabela 2 ). 


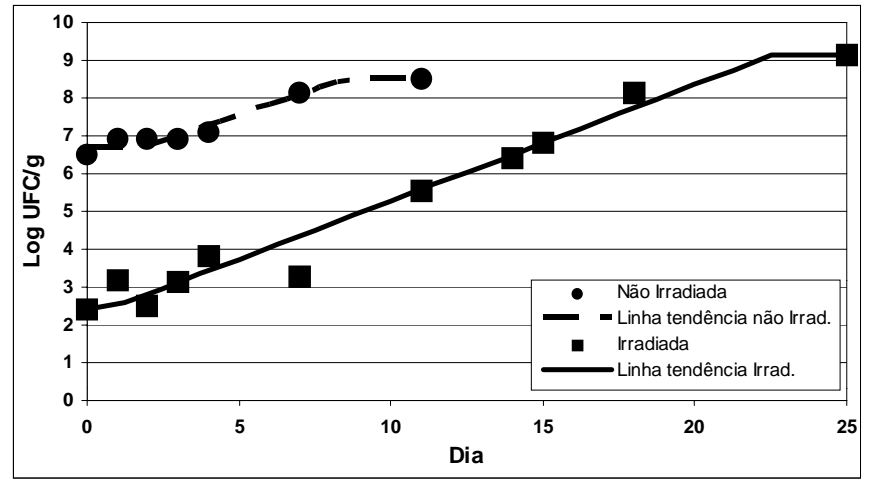

Figura 1 - Representação gráfica dos resultados das contagens de bactérias heterotróficas aeróbias mesófilas viáveis e suas respectivas linhas de tendência em amostras controle e submetidas à irradiação gama (3kGy) de peitos de frango refrigerados e armazenados durante 11 e 25 dias, respectivamente.

Tabela 1 - Contagem (Log UFC/g) de bactérias heterotróficas aeróbias mesófilas viáveis em amostras controle e submetidas à irradiação gama (3kGy) de peitos de frango refrigerados armazenados durante 11 e 25 dias, respectivamente.

\begin{tabular}{ccc}
\hline Dia & Não Irradiada & Irradiada \\
\hline 0 & 6,5 & 2,4 \\
1 & 6,9 & 3,2 \\
2 & 6,9 & 2,5 \\
3 & 6,9 & 3,1 \\
4 & 7,1 & 3,8 \\
7 & 8,1 & 3,3 \\
11 & 8,5 & 5,6 \\
14 & & 6,4 \\
15 & & 6,8 \\
18 & & 8,2 \\
25 & & 9,2 \\
\hline \hline
\end{tabular}

Tabela 2 - Resultados dos parâmetros de crescimento (tempo de duplicação e fase de latência em horas e, contagem na fase estacionária de crescimento em Log UFC/g) de acordo com Baranyi (1994).

\begin{tabular}{lccc}
\hline \hline & $\begin{array}{c}\text { Tempo de } \\
\text { duplicação }\end{array}$ & $\begin{array}{c}\text { Fase de } \\
\text { latência }\end{array}$ & $\begin{array}{c}\text { Contagem na fase } \\
\text { estacionária de } \\
\text { crescimento }\end{array}$ \\
\hline Não Irradiada & 27,1 & 45,6 & 8,5 \\
Irradiada & 23,5 & 19,2 & 9,0 \\
\hline \hline
\end{tabular}

Os resultados relativos à redução da carga bacteriológica no peito de frango irradiado estão em acordo com as conclusões de diversos autores (Katta et al., 1991; Lescano et al., 1991; Thayer, 1994; Tarboush et al., 1997; Spoto et al., 1999), que verificaram que o tratamento tecnológico da irradiação é eficaz na redução microbiana do frango e seus produtos.
Embora alguns autores (Lescano et al. 1991; Tarboush et al. 1997; Spoto et al. 1999) tenham empregado doses diferentes da utilizada nesta pesquisa, pode-se afirmar, de acordo com Klinger et al. (apud Xavier e Beraquet, 1992), que a redução nas contagens totais é proporcional à dose aplicada. Farkas (1987) relata que não existe consenso sobre a dose exata a ser utilizada, pois cada alimento possui uma população microbiana inicial distinta. Tal afirmação justifica as variações nas contagens registradas nesta pesquisa.

Ao considerar o efeito da irradiação gama no prolongamento da vida útil do frango, em termos bacteriológicos, Tarboush et al. (1997), utilizando dose de 2,5 kGy, observaram que o grupo controle apresentou sinais de deterioração a partir do $6^{\circ}$ dia (contagens logarítmicas de 8,0 ) enquanto as amostras irradiadas apresentaram tais contagens somente no $18^{\circ}$ dia. Os autores citados concluíram que a irradiação de frango aumentou em duas vezes a sua vida útil. Entretanto, Ayres (1950) considera que ao alcançarem-se contagens logarítmicas entre 7,2 e 8,0, já se observam odores anormais, e percebe-se formação de mucosidade quando o valor é de $\sim 8,0$ (Log UFC/ $\mathrm{cm}^{2}$ ). Neste experimento, consideraramse contagens de $10^{7} \mathrm{UFC} / \mathrm{g}$ para indicar condições sensoriais insatisfatórias. Tais contagens foram registradas no grupo controle a partir do $4^{\circ}$ dia, enquanto as amostras irradiadas alcançaram tal nível somente no 15 dia, resultando num prolongamento da vida útil de $\sim 3$ vezes. Estes resultados podem ser comparados aos de Tarboush et al. (1997), que, ao utilizarem a dose de 2,5 kGy, obtiveram um aumento de vida útil de carne de frango irradiada de $\sim 2$ vezes.

Ao analisar-se o $\mathrm{pH}$ do peito de frango, observou-se que 0 grupo controle apresentou variação de 5,9 a 6,5 e as amostras irradiadas obtiveram resultados semelhantes, com variação entre 5,9 e 6,8 (Tabela 3 e Figura 2). Embora não tenha sido realizada a identificação dos microrganismos presentes, pode-se suspeitar, segundo Barnes e Impey (1968), que variações de $\mathrm{pH}$ entre 6,4 e 6,7 podem ser atribuídas às bactérias Acinetobacter, Alteromonas e Pseudomonas; já variações entre 5,7 e 5,9 podem caracterizar Pseudomonas e outras bactérias.

Tabela 3 - pH em amostras controle e submetidas à irradiação gama (3kGy) de peitos de frango refrigerados armazenados durante 11 e 25 dias, respectivamente.

\begin{tabular}{ccc}
\hline \hline Dia & Não Irradiada & Irradiada \\
\hline 0 & 5,9 & 6,2 \\
1 & 6,1 & 6,1 \\
2 & 6,1 & 5,9 \\
3 & 6,2 & 6,3 \\
4 & 6,0 & 6,1 \\
7 & 6,2 & 6,1 \\
11 & 6,5 & 6,0 \\
14 & & 5,9 \\
15 & & 5,9 \\
18 & & 6,3 \\
25 & & 6,8 \\
\hline \hline
\end{tabular}




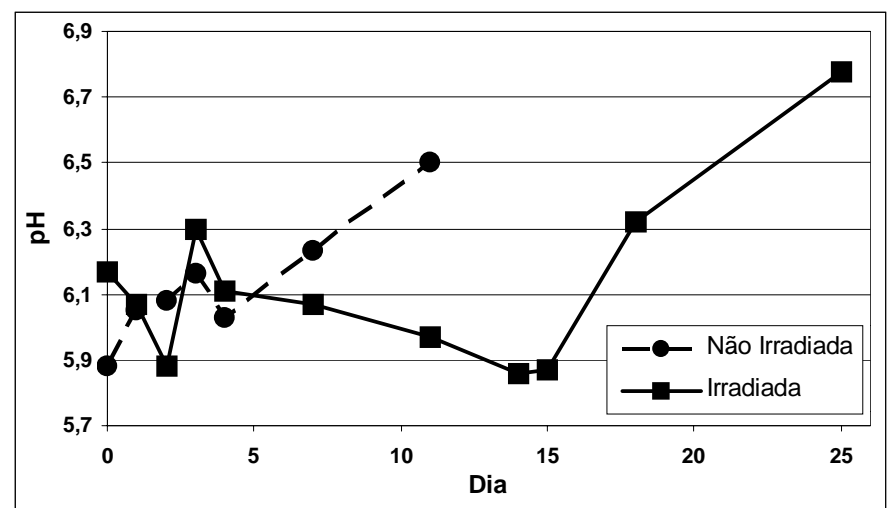

Figura 2 - pH em amostras controle e submetidas à irradiação gama (3kGy) de peitos de frango refrigerados armazenados durante 11 e 25 dias, respectivamente.

Na Tabela 4 e Figura 3 estão expostos os resultados obtidos na avaliação de temperatura. Verificou-se que a temperatura no momento da colheita foi de $10,3^{\circ} \mathrm{C}$, sendo que em seguida o produto foi armazenado em recipiente isotérmico com gelo, vindo a reduzir-se a partir do $1^{\circ}$ dia, registrando-se $2,2^{\circ} \mathrm{C}$. Observaram-se pequenas oscilações até o $25^{\circ}$ dia de armazenamento. Já a temperatura mínima variou entre $-1,6$ e $0,2^{\circ} \mathrm{C}$.

Tabela 4 - Resultado da variação de temperatura $\left({ }^{\circ} \mathrm{C}\right)$ da amostra de peito de frango refrigerados e suas variações mínima e máxima em 25 dias de armazenamento.

\begin{tabular}{cccc}
\hline \hline Dia & Amostra & Mínima & Máxima \\
\hline 0 & 10,3 & - & - \\
1 & 2,2 & 0,2 & 3,5 \\
2 & 0,2 & 0,2 & 3,5 \\
3 & -1 & $-1,0$ & 3,5 \\
4 & 1 & $-1,0$ & 3,5 \\
6 & $-1,2$ & $-1,2$ & 3,5 \\
7 & $-1,4$ & $-1,4$ & 3,5 \\
8 & $-1,4$ & $-1,4$ & 3,5 \\
11 & 0,6 & $-1,6$ & 3,5 \\
12 & 0,6 & $-1,6$ & 3,5 \\
14 & 0,6 & $-1,6$ & 3,5 \\
15 & 2,4 & $-1,6$ & 3,5 \\
18 & 0,6 & $-1,6$ & 3,5 \\
21 & 0,6 & $-1,6$ & 3,5 \\
25 & 3,5 & $-1,6$ & 3,5 \\
\hline \hline
\end{tabular}

\section{Referências}

ABEF - Associação Brasileira de Exportadores e Produtores de Frangos. Estatísticas no mercado mundial. Disponível na Internet via: <http:/ /www.abef.com.br/estatisticas/mercado.asp>. Acesso em: 1 abril 2002. ALLEN, C. D.; RUSSEL, S. M.; FLETCHER, D. L. The relationship of broiler breast meat color and $\mathrm{pH}$ to shelf-life and odor development. Poultry Science, v. 76, p. 1042-1046, 1997.

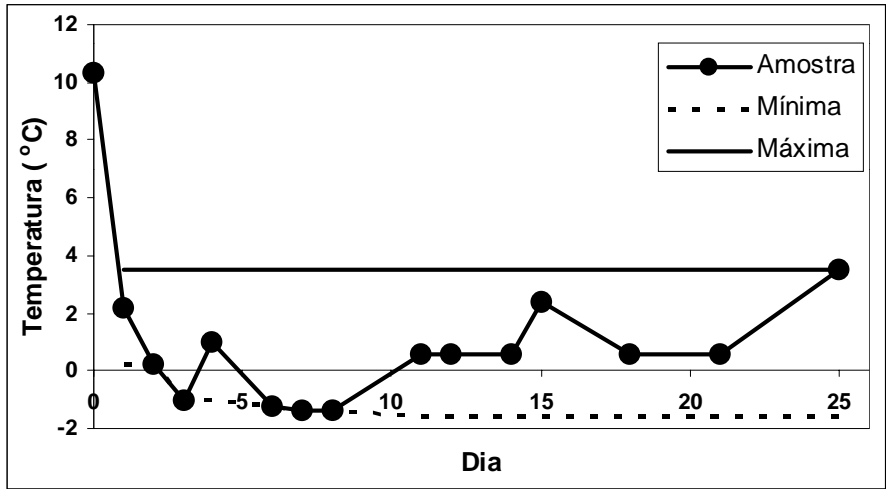

Figura 3 - Resultado gráfico da variação da temperatura da amostra de peito de frango refrigerado e suas variações máxima e mínima em 25 dias de armazenamento.

Em relação à qualidade final do produto, Johnston e Tompkin (apud Allen et al., 1997) afirmam que a obtenção de um resultado qualitativo satisfatório depende da contaminação inicial, temperatura de estocagem, tipo de embalagem, composição final do produto, potencial de oxirredução, do pH e da umidade. Neste trabalho, analisou-se a carga bacteriana nas amostras controle e nas submetidas à irradiação, a variação de $\mathrm{pH}$ nas respectivas amostras e a temperatura da amostra durante o período de estocagem. De acordo com esses autores, pode-se afirmar que: a baixa contagem registrada nas amostras tratadas pelo processamento tecnológico da irradiação, aliada à baixa temperatura de armazenamento, contribuiu para a obtenção do maior prazo de vida comercial observado.

\section{Conclusão}

De acordo com os resultados, pode-se concluir que a irradiação não proporcionou alterações nos valores de $\mathrm{pH}$ em relação às amostras controle. Considerando-se a baixa temperatura mantida durante todo o experimento, cabe afirmar que este fator, aliado à tecnologia de irradiação, contribuiu para o prolongamento da vida útil do peito de frango mantido sob refrigeração. Observou-se, também, que a irradiação gama foi eficaz na redução da contagem de bactérias heterotróficas aeróbias mesófilas em pelo menos quatro unidades logarítmicas, o que, em termos bacteriológicos, aumentou o tempo de vida útil do peito de frango refrigerado em aproximadamente três vezes.

Apesar da constatação da eficiência da tecnologia de irradiação avaliada nesta pesquisa, deve-se ressaltar que, qualquer que seja o procedimento utilizado na obtenção de produtos de melhor qualidade e maior tempo de vida comercial, este nunca deverá substituir os procedimentos de boas práticas de manipulação preconizada na indústria alimentícia.

AYRES, J. C.; OGIRLREY, W. S.; STEWART, G. F. Post mortem changes in stored meats. I. Microorganisms associated with development of slime on eviscerated cut-up poultry. Food Technology, v. 4, p. 199205, 1950.

BARANYI, J.; ROBERTS, T. A. A dynamic approach to predicting bacterial growth in food. International Journal of Food Microbiology, v. 23, p. 277-294, 1994. 
BARNES, E. M.; IMPEY, C. S. Psychrophilic spoilage of poultry. Journal Applied Bacteriology, v. 31, p. 97-107, 1968.

COMISSION OF EUROPEAN COMMUNITIES, Evaluation of hygienic problems related to the chilling of poultry carcasses. Information on Agriculture n²2, EEC, Brussels, 1976.

FARKAS, J. Decontamination, including parasite control, of dried, chilled and frozen foods by irradiation. Acta Alimentaria, v. 16, n. 4, p. 351384, 1987.

FDA - FOOD AND DRUG ADMINISTRATION. Irradiation of poultry. Federal Register, v. 55, p. 18.538, 1990.

GCIIA-GRUPO CONSULTIVO INTERNACIONAL DE IRRADIAÇÃODE ALIMENTOS. Hechos sobre irradiación de alimentos. 2000. 46 p.

GERMANO, P. M. L.; GERMANO, M. I. S. Higiene e vigilância sanitária de alimentos. Varela: São Paulo, 2001.629 p.

GILL, C. O. Microbial interactions with meats. In: Meat Microbiology (Ed. Brow, M. D.). Applied Science Publishers, London. p. 225-264. 1982.

JONHSTON, R. W.; R. B. TOMPKIN, Meat and poultry products. In: C. VANDERZANT and D. F. PLITTSTOERSSER. Compendium of methods for the microbiological examination of food. Ed. American Public Health Association, Washington, D.C. p. 822, 1992.

KATTA, S. R.; RAO, D. R.; SUNKI, G. R; CHAWAN, C. B. Effect of gamma irradiation of whole chicken carcasses on bacterial loads and fatty acids. Journal of Food Science, v. 56, n. 2, p. 371-372, 1991.

KLINGER, I.; FUCHS, V.; BASKER, D. Irradiation of broiler chicken meat. Israel Journal Veterinary Medicine, v. 42, n. 3, p. 181-192, 1986.
LESCANO, G.; NARVAIZ, P.; KAIRIYAMA, E.; KAUPERT, N. Effect of chicken breast irradiation on microbiological, chemical, and organolepitic quality. Lebensmittel Wissenschaft und Technologie, v. 24, n. 2, p. 130-134, 1991.

SPOTO,C.R.;GALLO, C.A.;DOMARCO, R. A.;ALCARDE, A. R.;WALDER, J. M. M.; BLUMER, L. Radiação gama na redução da carga microbiana de filés de frango. Ciência e Tecnologia de Alimentos, v. 19, n. 3, 1999.

SWANSON, K. M. J.; BUSTA, F. F.; PETERSON, E. H., JOHNSON, M. G. Colony Count Methods. In: Vanderzant, C. and Splittstoesser, D. F. Compendium of Methods for the Microbiological Examination of Foods. 3ed: washington: American Public Health Association (APHA), Cap. 4, p. 75-95, 1992.

TARBOUSH, H. M. A.; KAHTANI, H. A. A.; ATIA, M.; ARAB, A. A. A; BAJABER, A. S; MOJADDIDI, M. A. E. Sensory and microbial quality of chicken as affected by irradiation and post irradiation storage at $4.0^{\circ} \mathrm{C}$. Journal of Food Protection, v. 60, n. 7, p. 761-770, 1997.

THAYER, D. Extending shelf life of poultry and red meat by irradiation processing. Journal of Food Protection, v. 56, n. 10, p. 831-833, 846, 1993.

WHO/FAO/IAEA - World Health Organization, Food and Agriculture Organization, and International Atomic Energy Agency. International Consultative Group on Food Irradiation - 1989. Consultation on microbiological criteria for foods to be further processed including by WHO/EHE/FOS, Geneva, 1989.

XAVIER, C. V. A.; BERAQUET, N. J. Vida de prateleira da carne de frango refrigerada: alternativas tecnológicas. II - Métodos de descontaminação. Coletânea ITAL, v. 24, n. 2, p. 121-128, 1994. 